\title{
Além do Estado: Governança Privada na Interface entre Mudança Climática e Comércio Internacional
}

\author{
Beyond the State: Private Governance at the Interface between \\ Climate Change and International Trade
}

Karina Marzano Franco

\begin{abstract}
Resumo: este artigo engloba a análise mais ampla do nexo comércio-clima, uma modalidade importante, mas ainda pouco pesquisada, de interação política. Ao realizar levantamento e revisão crítica da literatura, o texto apresenta conexões entre mudança climática e comércio internacional, e desafios para futuras agendas de pesquisa. Trata-se de um artigo teórico que se concentra em atores não-estatais, indo além do Estado como unidade de análise. Visto que esses atores se tornam ainda mais relevantes em um contexto de crise do multilateralismo, a análise se baseia em uma abordagem de governança privada que avalia o papel dos atores privados no esverdeamento das cadeias de fornecimento globais. Uma melhor compreensão de como as exigências climáticas são impostas por empresas a fornecedores nacionais e estrangeiros revela insights importantes sobre o impacto dos arranjos de governança privada na promoção do desenvolvimento sustentável e no cumprimento de metas climáticas.
\end{abstract}

Palavras-chave: Mudança Climática; Comércio Internacional; Governança; Atores Privados

\begin{abstract}
: this article encompasses the broader analysis of climate-trade nexus, an important but still under-researched modality of policy interaction. By carrying out a critical literature review, the text presents connections between climate change and international trade, and challenges for future research agendas. This is a theoretical article that focuses on non-state actors, going beyond the state as unit of analysis. As these actors become even more relevant in a context of crisis in multilateralism, the analysis relies on a private governance approach, assessing the role of private actors in greening global supply chains. A better understanding of how climate requirements are imposed by firms on domestic and foreign suppliers unravels important insights into the impact of private governance arrangements on fostering sustainable development and achieving climate targets.
\end{abstract}

Keywords: Climate Change, International Trade; Governance; Private Actors

\section{Introdução}

Os regimes internacionais de mudança climática e de comércio apresentam inúmeras interfaces que merecem ser estudadas, a fim de contribuir para o êxito dessas agendas em favor do desenvolvimento sustentável das nações e da melhoria das condições de vida das gerações atuais e futuras. Para isso, um importante ponto de partida é reconhecer que os regimes comercial e climático não são apenas complexos 
(Keohane; Victor, 2011, p. 6) e fragmentados; eles também vão além do nível das relações estatais, ou como sugere o título deste trabalho, além do Estado. Trata-se do chamado "triângulo de governança" (ABBOTT, 2012, p. 574), que inclui, além de instituições estatais, também empresas e sociedade civil.

Levando-se em conta os contextos atuais de oportunidades e de desafios de cada uma das agendas, este artigo teórico se dedica a entender a relação entre clima e comércio internacional a partir da atuação de atores não-estatais. Isso porque esses atores se tornam ainda mais relevantes em um contexto de crise do multilateralismo e de paralisia decisória de instituições intergovernamentais, sendo o exemplo da Organização Mundial do Comércio (OMC) o mais evidente atualmente. Por conseguinte, este trabalho busca contribuir para o avanço do debate teórico na interseção entre governança climática e comércio internacional, a partir do reconhecimento da multiplicidade de atores envolvidos. Em especial, o debate crítico da literatura aqui proposto dedica-se ao entendimento da atuação de atores não estatais privados, que têm assumido o papel de legisladores (VANDENBERGH, 2007, p. 918), influenciando, simultaneamente, o desenvolvimento das agendas de clima e de comércio internacional.

O levantamento e a revisão crítica da literatura realizados neste artigo focalizam nas mencionadas obras de Keohone, Abbot e Vandenbergh que, respectivamente, apontam para a complexidade do regime climático, a multiplicidade de atores, e o papel dos atores privados. A estes autores principais soma-se a revisão de textos complementares que elucidam modalidades de governança privada. Para tanto, este artigo divide-se em duas partes. A primeira dedica-se ao melhor entendimento da interação entre o regime internacional de mudança climática e de comércio internacional. A segunda destina-se à definição e à análise do conceito de governança privada aplicada à mudança climática, suas potencialidades e desafios.

Visando responder à pergunta sobre o que é a chamada governança climática privada e como ela tem afetado o nexo clima-comércio internacional, trabalha-se com a hipótese de que a governança privada dispõe do potencial necessário de transformar a natureza e os termos do debate entre clima e comércio internacional, bem como a interface entre eles. A crescente participação de atores privados, no entanto, levanta preocupações sobre a prestação de contas e a legitimidade dos novos arranjos (BÄCKSTRAND, 2008, p. 78).

Como Pattberg (2005, p. 591) destaca,

Uma melhor compreensão da elaboração de regras privadas como um dos fenômenos emergentes na política mundial não apenas ampliará nossa compreensão teórica da governança global, mas também contribuirá para a tão necessária criação de instituições para um efetivo desenvolvimento sustentável (2005, p. 591, tradução nossa).

\section{O Nexo Clima-Comércio Internacional}

\section{Desenvolvimento Atual de Cada Regime Internacional}

Ambas as agendas de mudanças climáticas e de comércio internacional passaram, recentemente, por importantes atualizações. No regime comercial, a cooperação multilateral que resultou em um corpo extenso e complexo de direito internacional e de jurisprudência no contexto da OMC está sob pressão 
considerável, especialmente desde os impasses da Agenda de Desenvolvimento de Doha. O resultado é uma crescente proliferação de medidas protecionistas e de guerras comerciais, bem como o surgimento de iniciativas de comércio mini- e plurilaterais para além da OMC (Brandi; Berger; Bruhn, 2015, p. 2).

No regime global de mudanças climáticas, por sua vez, a cooperação multilateral fez progressos impressionantes no final de 2015, incluindo a conclusão de um novo e ambicioso tratado - o Acordo de Paris -, que é considerado um marco na cooperação internacional, englobando um compromisso universal de limitar o aquecimento global a $2^{\circ} \mathrm{C}$, acompanhado de planos de ação determinados pelos países: as chamadas Contribuições Nacionalmente Determinadas (NDCs, em inglês). Ao combinar uma abordagem universal com uma abordagem de baixo para cima (bottom-up), o acordo confere maior flexibilidade na escolha da medida doméstica para combater as mudanças climáticas, aumentando, consequentemente, o potencial para implicações comerciais (Droege; van Asselt; Das; Mehling, 2016, p. 13). Essa potencialidade de conflito confere maior relevância ao estudo do nexo clima-comércio internacional, buscando maneiras de facilitar o diálogo entre os regimes.

Assim como a política comercial vai além da OMC, incluindo uma série de iniciativas bi- e plurilaterais, sendo diretamente afetada por atores estatais e não-estatais, a governança das mudanças climáticas também excede a Convenção-Quadro das Nações Unidas sobre Mudança do Clima (UNFCCC) e o próprio Acordo de Paris. Argumenta-se que um regime global, abrangente e integrado, não é uma configuração viável para a governança das mudanças climáticas, principalmente devido à incerteza causada pela variada capacidade dos governos de implementar compromissos (Keohane; Victor, 2011, p. 16) e pela tendência de alguns a 'sub-reagir' a pressões climáticas (Howlett; Kemmerling, 2017, p. 2). Isso porque os avanços do regime climático são muito dependentes da vontade política de governantes e de sua capacidade de resposta às pressões exercidas pela sociedade civil. Assim como no caso do comércio internacional, as mudanças climáticas também apresentam um regime global muito fragmentado. Para alguns, o regime climático é, de fato, melhor descrito como um "Regime Complex", ou seja, um conjunto de regimes específicos fracamente acoplados (Keohane; Victor, 2011, p. 2). O "Regime Complex" configura-se em um sistema não hierárquico de instituições, capaz de abranger interesses de uma diversidade de atores. $O$ entendimento das características gerais e contextos atuais dos regimes de clima e de comércio internacional permitem seguir para a análise da interação entre eles.

\section{As Múltiplas Interfaces entre Clima e Comércio Internacional}

Comércio internacional e mudança climática apresentam várias interfaces. Por um lado, políticas nacionais como medidas regulatórias e incentivos econômicos para lidar com as mudanças climáticas podem afetar o comércio internacional. Por outro lado, o livre comércio impacta - positiva e negativamente - as emissões de gases de efeito estufa (GEE), aumentando, por exemplo, o uso de serviços de transporte e suas emissões, ou melhorando a eficiência energética e reduzindo custos de bens, serviços e tecnologias ambientalmente corretos. Há também discussões em andamento sobre a precificação de carbono, sobre ajustes de impostos fronteiriços para emissões e sobre reforma de subsídios aos combustíveis fósseis, apenas para mencionar alguns dos nexos mais evidentes entre as respectivas agendas (Goldthau; Keating; Kuzemko, 2018, p. 7; Droege; van Asselt; Das; Mehling, 2016, p. 39; BRANDI, 2017, p. 14). 
A relação entre clima e comércio internacional é, portanto, bidirecional e multifacetada. As normas de livre comércio impactam a agenda climática, mas também medidas implementadas para combater as mudanças climáticas afetam o funcionamento do comércio internacional. Tradicionalmente, regras comerciais têm sido vistas como empecilhos ao combate às mudanças climáticas, destacando-se a potencialidade de conflitos entre as duas agendas. Tal conflito seria majorado em vista da abordagem bottom-up empregada pelo Acordo de Paris, que, como vimos, ao fundar-se em medidas nacionais contra o aquecimento global, resultaria em maiores implicações comerciais (Droege; van Asselt; Das; Mehling, 2016, p. 13).

Um dos temas mais controversos é o protecionismo disfarçado, com impactos na competitividade, resultante da aplicação de barreiras não tarifárias sob o argumento de desrespeito às normas ambientais e climáticas (protecionismo verde), um problema recorrente em casos frente ao sistema de solução de controvérsias da OMC (KHOR, 2012, p. 72; YU, 2009, p. 2). De fato, a OMC tem se deparado cada vez mais com a necessidade de decidir casos relacionados a políticas nacionais climáticas, sobretudo sobre investimentos em energias renováveis (no total, são sete casos, entre 2010 e 2016, envolvendo temas como energia, renováveis e programa de feed-in tariff). Uma análise do case law da OMC permite perceber a recorrência de casos em que membros exportadores questionam critérios ambientais/ climáticos impostos pelos importadores como configurando formas de protecionismo e de regulação extraterritorial. Nos clássicos casos Shrimp/Turtle e Tuna/Dolphin, analisa-se se as barreiras impostas sob argumento ambiental encaixar-se-iam nas exceções gerais do artigo XX ( $\mathrm{g}$ ) do Acordo Geral de Tarifas e Comércio (GATT, em inglês). As exceções deste artigo permitem a aplicação de medidas relacionadas à conservação de recursos naturais esgotáveis, desde que não constituam arbitrária ou injustificada discriminação entre países ou disfarçada restrição ao comércio internacional (preâmbulo do artigo), devendo ser executadas conjuntamente com restrições à produção e ao consumo doméstico (requisito específico da alínea ' $g$ '). Casos mais recentes, ligados a leis e a políticas nacionais de energias renováveis lidam com temas como antidumping, subsídios e regras de conteúdo local que, na prática, geram efeitos econômicos negativos em países exportadores, com encargos financeiros e tecnológicos para países produtores. São exemplos os casos Canada-Renewable Energy, levado pelo Japão contra programa de feed-in tariff canadense; e o caso China-Measures Concerning Wind Power Equipment, levado pelos EUA contra subsídios chineses, entre outros.

No entanto, percebe-se uma dicotomia entre a natureza de decisões case by case no contexto da OMC versus um conflito que se caracteriza como sistemático entre políticas climáticas nacionais, particularmente de renováveis, e a obrigação de não discriminação. A recorrência desse conflito demanda um enfrentamento da questão de modo abrangente, e não caso a caso, o que conferiria maior segurança jurídica. Por isso discute-se a necessidade de uma interpretação authorizative do Artigo XX do GATT, a fim de clarificar o escopo das exceções às obrigações comerciais, bem como a inclusão de especialistas em clima no sistema de solução de controvérsias da OMC (Droege; van Asselt; Das; Mehling, 2016, p. 46).

Recentemente, surgem esforços para se desenvolver uma abordagem mais positiva do nexo clima-comércio, em que as regras comerciais podem assumir o papel de facilitadores da implementação do Acordo de Paris, desde que haja coordenação das agendas (Droege; van Asselt; Das; 
Mehling, 2018, p. 26). Um dos casos mais evidentes de política comercial ajudando no combate às mudanças climáticas é o esforço pelo fim dos subsídios a combustíveis fósseis. Ao afetar os preços dos combustíveis fósseis, subsídios distorcem comércio e investimento; uma reforma do Acordo da OMC em Subsídios e Medidas Compensatórias, no entanto, enfrentaria o desafio de precisar alcançar o consenso entre todos os Membros. Outra abordagem positiva das regras comerciais em prol do combate às mudanças climáticas inclui a liberalização do comércio de bens e serviços ambientais, incentivando o desenvolvimento de tecnologias limpas. Destaca-se uma iniciativa plurilateral no contexto da OMC de elaboração do Acordo de Bens Ambientais (Environmental Goods Agreement - EGA), que, com o fracasso da opção multilateral, ofereceria uma alternativa para disseminar tecnologias e produtos a partir da redução tarifária.

O potencial complementar das agendas de clima e de comércio aponta para a necessidade de melhorar as interações entre os regimes a fim de se alcançar uma exitosa implementação do Acordo de Paris, compatibilizada com as regras de livre comércio. O contexto atual, no entanto, revela a necessidade de se pensar caminhos adicionais à abordagem multilateral/intergovernamental tradicional.

\section{Multilateralismo em Crise}

As dificuldades de avanço nas negociações e sua forte dependência em relação à vontade política dos membros sugerem uma perda de relevância da OMC, configurando-se como um dos casos mais paradigmáticos da crise atual do sistema multilateral. De fato, a paralisação da Rodada Doha e medidas protecionistas como as tarifas sobre aço e alumínio adotadas pelo presidente estadunidense Donald Trump levaram muitos a anunciar a morte daquela instituição (ALDEN, 2018). Há, porém, um paradoxo, na medida em que o enfraquecimento da inovação legislativa multilateral em matéria de comércio ocorre simultaneamente à proeminência continuada do sistema de solução de controvérsias da OMC como ferramenta institucional para oferecer resposta legal, sobretudo em casos de conflitos com políticas climáticas.

Do mesmo modo, apesar da entrada em vigor do Acordo de Paris, mudanças de governo, sendo os EUA o caso mais notório, apontam para um menor comprometimento com a implementação de uma economia de baixo carbono. Na interface entre clima e comércio internacional, ademais da crescente proliferação de medidas protecionistas e de guerras comerciais, crescem iniciativas mini- e plurilaterais de comércio, muitas das quais incluem cláusulas climáticas e ambientais. Novamente, as consequências dessa tendência são dúbias. Acordos regionais podem apresentar uma interessante maneira de introduzir e testar novas regras em clima e comércio internacional (BRANDI; BERGER; BRUHN, 2015, p. 3), e estabelecer padrões de proteção climática a serem seguidos pelos demais países, evitando um nivelamento regulatório por baixo (race to the bottom) (Droege; van Asselt; Das; Mehling, 2016, p. 46). Os interesses para o estabelecimento dessas regras, porém, devem ser analisados, bem como se deve buscar entender como tais regras impactam os países que não participam de sua formulação, evitando que, novamente, o fantasma do protecionismo disfarçado reapareça.

A União Europeia, por exemplo, foi pioneira em incluir regras ambientais em acordos comerciais (EU-green clause), e, recentemente, tem se recusado a assinar acordos com países que não ratificaram Paris. Ademais, anteriormente à iniciativa do EGA vista acima, cujas negociações estão paralisadas 
desde 2016, outros acordos regionais também abordaram o tema dos bens ambientais, como no caso da Cooperação Econômica da Ásia-Pacífico (APEC, em inglês), em que mais de 20 membros assinaram, em 2012, um compromisso de reduzir tarifas em uma lista de bens ambientais. Terceiros países, porém, questionam os impactos de sua não participação na formulação e na implementação dessas regras.

Essa fragmentação do regime comercial não é um desafio recente. O fenômeno conhecido como "spaghetti bowl" (Bhagwati, 1995, p. 4) aponta para a complexidade do sistema comercial oriunda da proliferação de acordos de livre comércio. O impacto desse fenômeno para agenda climática, porém, é menos conhecido e, apenas recentemente, com o aprofundamento da crise da OMC e a elaboração do Acordo de Paris, tem-se pensado quais os efeitos do enfraquecimento do multilateralismo comercial para o combate das mudanças climáticas (BRANDI; BERGER; BRUHN, 2015, p. 3). Como veremos abaixo, a crise do multilateralismo e a dificuldade de coordenar as agendas dentro do modelo intergovernamental não somente questionam o papel de acordos bi- e plurilaterais de comércio, como também demandam refletir sobre o papel de atores não-estatais na criação de normas e regras internacionais.

\section{Desafios de Coordenação entre os Regimes Internacionais}

Não há regras claras nem instituições intergovernamentais coordenando de modo abrangente a interface entre os regimes climático e comercial. A UNFCCC, o GATT/OMC e o Acordo de Paris são todos exemplos de tratados internacionais, cada um com seu campo específico de atuação, não havendo hierarquia de aplicação entre suas normas. Dentro do regime comercial, o preâmbulo do Acordo de 1995 que estabelece a OMC reconhece a finalidade do regime comercial de permitir o uso ótimo dos recursos do mundo conforme o objetivo do desenvolvimento sustentável. Naquele mesmo ano foi criado o Comitê da OMC em Comércio e Meio Ambiente (CTE, em inglês), para promover a interação harmônica entre os dois temas. A Declaração Ministerial de Doha (parágrafo 31) reconhece explicitamente a relação entre regras da OMC e obrigações comerciais específicas presentes em acordos ambientais, instruindo o trabalho do CTE. Durante a Direção-Geral de Pascal Lamy, o tema climático ganhou relevância no âmbito da OMC, refletido no relatório conjunto desta instituição com o então Programa das Nações Unidas para o Meio Ambiente (PNUMA, atual ONU Meio Ambiente) de 2009, que, pela primeira vez, explorava as conexões clima-comércio. No entanto, a abordagem de single-undertaking e a dificuldade de consenso, sobretudo tendo-se em vista opiniões divergentes entre países desenvolvidos e em desenvolvimento, bloquearam o avanço do tema, somente tendo ocorrido tímidos progressos nos Pacotes de Bali e de Nairóbi, respectivamente em 2013 e 2015.

Já no regime climático, o Acordo de Paris não faz referência explícita a regras comerciais, e as razões principais para tanto são também as opiniões divergentes entre países desenvolvidos e em desenvolvimento sobre o tema, o que dificultaria a aprovação do texto do acordo. O Artigo 3(5) da UNFCCC estabelece o princípio de que medidas tomadas para combater as mudanças climáticas, incluindo as unilaterais, não devem constituir um meio de discriminação arbitrária e injustificável, nem uma restrição disfarçada ao comércio internacional. Países desenvolvidos, no entanto, barraram sucessivas propostas dos países em desenvolvimento, com destaque para a atuação da Índia, 
que defende, por exemplo, a inclusão no acordo de uma proibição explícita de aplicação unilateral de medidas comerciais com base em argumento climático (UNFCCC, 2011, p. 5).

Embora a palavra "comércio" não seja mencionada no Acordo de Paris, as políticas comerciais têm um papel importante no combate às mudanças climáticas, e cerca de metade das NDCs implica uma referência direta a elementos comerciais (BRANDI, 2017, p. 24). Além disso, há potenciais implicações comerciais das NDCs sempre que medidas taxam, subsidiam e regulam atividades econômicas nacionais que se relacionam direta ou indiretamente com a participação comercial de outros países. Isso envolve discussões sobre elaboração de políticas industriais, com impactos em concorrência desleal, por exemplo, ao se adotar medidas que buscam contornar o chamado carbon leakage, isto é, o risco de transferir demanda para produtos importados mais baratos que não se submetem à precificação de carbono. Propostas de adoção de medidas na fronteira (border carbon adjustments) para mitigar este efeito precisam, porém, compatibilizar-se com as regras da OMC.

O Acordo de Paris e as NDCs aumentam a demanda para clarificar a interação entre os regimes, gerando riscos, mas também oportunidades. Isso porque, ao mesmo tempo em que falta orientação, há espaço para novas regras que apoiem mutuamente as agendas. Até o momento, os regimes de comércio e de clima coexistem sem maiores fricções, mas expectativas futuras e o potencial de aumento das disputas relacionadas a clima demandam melhor coordenação das agendas. Já que os dois regimes estão em crossroads, há uma oportunidade de criação de novas regras e procedimentos que beneficiem clima, comércio e desenvolvimento. Nesse sentido, interessa estudar quais atores têm capacidade para inovação legislativa, ou seja, para atuarem como promotores de regras e normas.

Sugestões de reformas dentro do próprio sistema multilateral da OMC incluiriam medidas como o aumento de transparência por meio da criação de um Comitê em Comércio, Meio Ambiente e Mudanças Climáticas na OMC ou o aumento da coordenação de órgãos existentes na OMC e na UNFCCC (Droege; van Asselt; Das; Mehling, 2016, p. 42). Opções de reformas legais como emenda, waiver, interpretação authorizative e cláusula de paz seriam difíceis de ser implementadas no curto prazo e arriscam dar espaço a protecionismos na forma de defesa climática. Há, portanto, reduzidas chances de reforma institucional partindo dos Estados no contexto atual, sendo que a cooperação bi- e plurilateral entre clima e comércio fora da OMC, ainda que possa trazer benefícios, aumenta o risco de aprofundar a fragmentação do regime de comércio internacional. Com a falta de apoio político no curto prazo para reformar a OMC, é importante analisar o papel dos atores privados e entender como eles assumem, em substituição ou de modo complementar, a função de inovar nas regras e procedimentos, e avaliar as potencialidades e os desafios envolvidos na governança climática privada.

\section{Governança Climática Privada}

\section{Definição e Potencialidades}

Os regimes de governança comercial e climática não são apenas fragmentados. Eles envolvem uma multiplicidade de atores, indo além do Estado como unidade de análise. De fato, a governança pode ser 
definida como a coordenação das atividades de Estados e de uma "vasta gama de atores e sistemas de regras que exercem autoridade na busca de objetivos fora das jurisdições nacionais" (ROSENAU, 2000, p. 172). O chamado "triângulo de governança" (ABBOTT, 2012, p. 574), que inclui organizações estatais, empresas e sociedade civil, oferece uma abordagem complementar e mais abrangente para analisar o "Regime Complex" definido por Keohane para mudanças climáticas, uma teoria ainda muito centrada no papel do Estado. Reconhecendo a "explosão cambriana de instituições transnacionais, padrões, arranjos financeiros e programas" (p. 571) em mudanças climáticas, Abbott mapeia um diferente domínio da governança do clima que, em vez de se concentrar em instituições interestatais, sugere um conjunto diversificado de esquemas transnacionais que inclui atores privados nas análises sobre o regime.

Segundo a teoria construtivista das relações internacionais (Wendt, 1992, p. 406), regimes são entendidos como arenas dentro das quais os Estados e demais atores passam a definir, intersubjetivamente, interesses e normas. Esses diversos atores que participam dos regimes, públicos e privados, operam em redes transnacionais em múltiplas escalas, isto é, interagem regularmente através das fronteiras nacionais (BETSILL; BULKELEY, 2004, p. 474). Ao reconhecer que os Estadosnação não são os únicos atores envolvidos na formação e na manutenção de regimes, estudos recentes de governança ampliam seu escopo e perfilham múltiplos efeitos decorrentes do envolvimento de atores não-estatais, incluindo grupos empresariais, nas arenas comercial e climática. Mais do que simplesmente adicionar novos atores à equação, novas pesquisas foram conduzidas, por exemplo, para examinar o papel das redes transnacionais e como elas alteram a natureza da governança ambiental global, sendo um dos casos mais relevantes a atuação de redes de cidades (BETSILL; BULKELEY, 2004, p. 476), como a rede Cities for Climate Protection (CCP) e o C40 Cities Climate Leadership Group. Apesar de as cidades serem atores estatais subnacionais, portanto não são exemplos de governança privada para o clima, a análise de sua atuação ajuda a compreender o caráter transnacional dessas redes. A expressão "transnacional" permite reconhecer que essas redes são globais, e não necessariamente internacionais, uma vez que o Estado-nação nem sempre participa da nova governança e pode, inclusive, ser ignorado por completo em alguns esquemas.

Em termos de governança privada, os atores não apenas desempenham um papel na implementação e no monitoramento de acordos internacionais, mas também no desenvolvimento paralelo da elaboração de regras cooperativas de política climática e comercial (FALKNER, 2003, p. 76). Há, inclusive, uma tendência recente de cooperação entre atores privados antagônicos, ou seja, antigos adversários, como Organizações Não-Governamentais (ONGs) e empresas (PATTBERG, 2005, p. 590), resultando na cooperação entre atores com e sem fins lucrativos. Esse tipo de arranjo também pode ser descrito como fenômeno regulatório das coalizões Baptist-bootlegger (Yandle, 1983, p. 12), em que grupos considerados adversários naturais se unem, algo muito comum, atualmente, em medidas de apoio a energias renováveis, por exemplo.

A criação e/ou implementação de normas e de regras transnacionais específicas por atores privados em cooperação constituem um deslocamento subsequente das formas tradicionais de governança pública para governança privada, que, ao conectar práticas locais e globais, complementam regras multilaterais. Pode-se falar, portanto, de uma governança difusa, que consiste na soma de muitas maneiras pelas quais indivíduos e instituições, públicas e privadas, gerenciam seus assuntos comuns 
(BETSILL; BULKELEY, 2004, p. 475). A legitimidade desse tipo de arranjo abarca a possibilidade de desenvolver uma estrutura flexível descentralizada, de natureza colaborativa, veloz e com aproveitamento de expertise diversificada. São variados os modelos de governança privada (BÄCKSTRAND, 2008, p. 83): a autorregulação privada, a delegação a atores privados, a adoção pública de regulamentação privada, a co-regulação, a consulta e cooptação de atores privados, o lobbying privado, entre outros.

Assim sendo, a arquitetura contemporânea de governança climática é multifacetada e fragmentada, englobando tanta autoridade pública quanto privada (BÄCKSTRAND, 2008, p. 75). A governança privada refere-se, portanto, à existência de autoridade fora das estruturas políticas formais, em que o setor privado começa a elaborar suas próprias regras e padrões, que adquirem autoridade além do sistema internacional intergovernamental (PATTBERG, 2005, p. 590). Pattberg dedica-se a entender como esta "governança privada em escala global é construída e mantida" ( $p$. 589). Ao analisar as condições necessárias, específicas e gerais, ele desenvolve um modelo integrado para avaliar e compreender a emergência da governança privada. Seu enfoque resta na cooperação institucionalizada entre os atores empresariais (autorregulação) e os sistemas transnacionais de regras resultantes da cooperação entre os atores com e sem fins lucrativos (co-regulação). O estudo apresenta-se relevante na medida em que institucionalizações de longo alcance entre atores privados sem o envolvimento de governos ainda são largamente negligenciadas pelo debate acadêmico. $O$ atual processo de institucionalização privada entre uma ampla variedade de atores empresariais e sem fins lucrativos significa mais do que um "esverdeamento" da indústria baseado em cálculos de interesse racionalista. Em vez disso, redes transnacionais alteram o impacto dos atores privados na política mundial, em que estes constituem não apenas uma variável interveniente do sistema internacional, mas estabelecem regras que existem fora dele (PATTBERG, 2005, p. 590).

A pesquisa dessa nova forma de governança que alcança fins tradicionalmente públicos por meio da atuação privada seria de particular interesse para a análise da interface entre as agendas climática e comercial, visto que atores privados têm relevância em ambas as agendas e atuam também especificamente no nexo entre elas. A autorregulação de corporações transnacionais e a contratação ambiental privada são exemplos interessantes de como a governança privada vem preencher lacunas no regime climático e em sua interface com a política comercial, gerando impactos globais.

A contratação privada dentro da relação comercial pode, em particular, ter um enorme impacto na criação de novos padrões e regulamentos climáticos. O desempenho de empresas no "esverdeamento" das cadeias globais de valor, fenômeno conhecido como "o novo efeito Wal-Mart" (VANDENBERGH, 2007, p. 918), destaca como redes de contratos comerciais privados podem servir a uma função reguladora pública na arena ambiental global. Ao regular o comportamento de uma terceira empresa, por meio da contratação privada nas cadeias globais de valor, são impostos requisitos ambientais a fornecedores nacionais e estrangeiros, ampliando o impacto regulatório privado para além das fronteiras nacionais.

Muitas das maiores empresas em países desenvolvidos estão impondo requisitos ambientais contratuais privados a fornecedores e outros contratados em países em desenvolvimento/exportadores. As razões e motivações dessas empresas são diversificadas: preferência do consumidor, pressões de investidores, funcionários e gestores, objetivo de evitar responsabilidade ou antecipar a regulamentação 
do governo, e até mesmo necessidade de assegurar aos investidores a disponibilidade de matérias-primas no longo prazo (VANDENBERGH, 2007, p. 917). The Coalition for Environmental Responsible Economies (CERES), um grupo formado por investidores socialmente responsáveis e ambientalistas, por exemplo, foi responsável pela criação de princípios ambientais com engajamento de empresas para se alcançar compromissos coorporativos de longo prazo. A CERES exemplifica a importância da demanda privada por uma estrutura regulatória na ausência de respostas governamentais apropriadas (PATTBERG, 2005, p. 598). Ademais, ONGs, muitas vezes, participam usando pressão de consumidores, para exigir mudança de comportamento das corporações, que, por sua vez, influenciam cadeias de valor globais. Na prática, pressões sobre uma empresa em um país importador induzem-na a impor condições na forma de atributos ambientais do bem ou serviço, ou no processo de produção, a empresas em países exportadores. A elaboração privada de padrões ocorre de forma coletiva ou unilateral: no primeiro caso ocorre por meio de associações industriais, de colaboração entre ONGs e indústrias, e de certificações, e têm o potencial para afetar um grande número de empresas em muitos setores. No segundo, firmas importadoras ou corporações multinacionais respondem ao consumidor, cliente, investidor, funcionário ou à pressão de ONGs, afetando políticas que se aplicam a suas operações ou suas compras nos países exportadores (VANDENBERGH, 2007, p. 917). Assim, incentivos sociais, econômicos e legais para a proteção ambiental são traduzidos em requisitos contratuais privados, e passam a ser aplicados globalmente via cadeias de valor.

Corporações são, portanto, "reguladoras de seus fornecedores, de seus mutuários, de seus arrendatários comerciais e, às vezes, de seus clientes corporativos" (VANDENBERGH; GILLIGAN, 2017, p. 16). Como vimos, a Wal-Mart, maior empresa de varejo do mundo, aproveitando seu poder de compra, tem adotado medidas de incentivo para seus fornecedores se tornarem mais sustentáveis. Outro importante exemplo é a Apple, que pressiona por menores emissões de carbono de seus fornecedores na China, e, quando seus fornecedores demonstraram preocupações que não poderiam reduzir sua pegada de carbono por conta da oferta de eletricidade a carvão, ela desenvolveu parcerias para o fornecimento de energia renovável.

Dados recentes (CDP, 2018, p. 6) corroboram esta tendência ao mostrar que, ao passo que as maiores empresas do mundo contabilizam e relatam as emissões de gases de GEE de suas operações diretas e da eletricidade que adquirem (escopos 1 e 2), cresce a necessidade de considerar outras operações para além das diretas, incluindo emissões da cadeia de suprimento a montante e a jusante (escopo 3). As iniciativas de gerenciamento ativo das emissões do escopo 3 geralmente excedem as emissões sobre as quais empresas têm controle direto - emissões na cadeia de suprimentos são, em média, cerca de quatro vezes maiores do que as das operações diretas de uma empresa. Em 2017, cerca de 100 organizações representando o gasto anual de mais de 3 trilhões de dólares com aquisições solicitaram informações de aproximadamente 10.000 fornecedores por meio do CDP, anteriormente denominado Carbon Disclosure Project. Os dados abarcam cerca de 50 segmentos industriais diferentes, de mais de 80 países, onde fornecedores divulgaram reduções equivalentes a 551 milhões de toneladas de $\mathrm{CO}_{2}$ (mais do que as emissões totais de carbono do Brasil em 2016), com economias de custos associadas de 14 bilhões de dólares (CDP, 2018, p. 4). O potencial de ganho com a governança privada por meio da contratação em cadeias de valor globais 
ainda permanece bastante inexplorado, visto que somente $23 \%$ das empresas que responderam ao questionário do CDP relataram engajar seus fornecedores, ou seja, este índice representa oportunidades de negócios perdidas, reduções de carbono negligenciadas e economias financeiras não realizadas (CDP, 2018, p. 7).

No entanto, ainda que uma visão pluralista liberal exalte o caráter flexível, descentralizado e voluntário da governança climática orientada para o mercado, entendendo ser a atuação privada uma inovação institucional com o objetivo mesmo de reduzir o déficit democrático em instituições multilaterais, o surgimento de "parcerias climáticas transnacionais" levanta preocupações sobre a prestação de contas e a legitimidade dos novos arranjos (BÄCKSTRAND, 2008, p.79).

\section{Desafios da Governança Privada}

Da mesma forma que o "Regime Complex" tem suas vantagens em termos de adaptabilidade e flexibilidade, mas precisa atender a alguns critérios, como coerência e responsabilidade (Keohane; Victor 2011, p. 2), também a governança privada não acontece sem riscos de legitimidade. Existe uma inquietude sobre se a atuação ambiental privada satisfaz anseios democráticos de eficiência e de responsabilidade (VANDENBERG, 2007, p. 944; BÄCKSTRAND, 2008, p. 78), e respeita as regras de livre comércio. As empresas encontraram, por meio de regras de contratação, uma maneira de superar as barreiras tradicionais de soberania, para regular o comportamento ambiental de empresas que operam exclusivamente em outros países. Surge a apreensão se essa tendência configura uma forma de legislação extraterritorial empresarial e em que medida elas apoiam a realização de metas climáticas ou configuram protecionismo disfarçado e competição desigual. Questiona-se se as empresas importadoras estariam, por meio da influência no comportamento das exportadoras, externalizando ou internalizando o custo ambiental (VANDENBERG, 2007, p. 919). Dificuldades em accountability da governança privada preocupam, sendo necessário analisar como seria a prestação de contas, uma vez que, enquanto regra, as empresas privadas são responsáveis, sobretudo, perante seus investidores. Indaga-se se o aumento do poder corporativo significaria o fim do poder estatal soberano, ou se atores privados teriam atuação apenas complementar, na medida em que entes estatais e públicos ainda exercem a tomada de decisão exclusiva.

O reenquadramento da questão para reconhecer a relevância da governança climática privada gera várias mudanças conceituais. O ator impulsionador de reduções de emissões de gases de efeito estufa se expande do governo para incluir qualquer organização pública ou privada. Por sua vez, as ações que podem ser tomadas ampliam-se a partir de leis, políticas e programas do governo para abarcar também várias opções privadas, como requisitos de contratação da cadeia de fornecimento. Até mesmo a concepção de fontes de emissões muda, uma vez que atores e iniciativas privadas podem alcançar muitos tipos de fontes que são difíceis de serem reguladas pelo governo, incluindo famílias, pequenas empresas, empresas estrangeiras, organizações religiosas, universidades, hospitais e organizações cívicas e culturais (VANDENBERGH \& GILLIGAN, 2017, p. 3).

A crítica neo-gramsciana questiona a legitimidade de arranjos de governança privada, na medida em que eles resultariam na mercantilização das mudanças climáticas e no colonialismo/capitalismo do carbono, reforçando uma ordem climática neoliberal. Fala-se em um processo arriscado de privatização 
do regime - multilateralismo de mercado -, em que parcerias business-to-business autorreguladas entre grandes empresas transnacionais e governadas por responsabilidade de mercado e por considerações de reputação seriam mais dificilmente controladas pelos governos e pela sociedade. Alguns dos possíveis efeitos negativos incluiriam o aumento da influência do setor de negócios, riscos associados a assimetrias de poder, representação distorcida de partes interessadas, reforço do multilateralismo de elite, retirada da responsabilidade do Estado na produção de bens públicos (BÄCKSTRAND, 2008, p. 78), e greenwashing, ou seja, quando a disseminação de informações enganosas tem a intenção de ocultar o abuso ambiental, apresentando uma imagem pública positiva da empresa.

Percebe-se, portanto, que o processo de governança privada se expande de forma difusa, ainda sem solução satisfatória para os desafios de legitimidade e eficiência, que merecem atenção por agendas de pesquisa voltadas para o nexo clima-comércio.

\section{Conclusões}

Entusiastas de uma visão pluralista liberal tendem a abraçar a flexibilidade da governança climática voluntária e descentralizada orientada para o mercado (BÄCKSTRAND, 2008, p. 78). A governança climática privada na forma de contratação por empresas influenciando na cadeia de valores, mais especificamente, é vista como uma resposta ao aumento da exploração dos recursos globais comuns via crescimento do comércio internacional. Teme-se que este crescimento comercial poderia transferir indústrias para países exportadores com normas ambientais frouxas. A rede de normas privadas e de acordos surge como resposta a esse receio, influenciando o comportamento empresarial em temas nos quais Estados soberanos não estão dispostos ou são incapazes de resolver. Em teoria, normas climáticas privadas sugerem uma diminuição de danos ambientais do comércio internacional (VANDENBERGH, 2007, p. 918).

Ainda que possa ser encarada como uma valiosa estratégia de preenchimento de lacunas regulatórias (VANDENBERGH, 2007, p. 919) e de enfrentamento dos desafios de coordenação entre as agendas comercial e climática, a governança climática privada apresenta riscos em termos de responsabilização e controle democrático. Argumenta-se que a governança climática privada é preferível à alternativa, qual seja, uma regulamentação nacional e internacional frouxa (VANDENBERGH, 2007, p. 913). Até que ponto a atividade regulatória privada e difusa abre espaço para protecionismo disfarçado, competição desigual e má alocação de recursos econômicos ainda é um tema que demanda aprofundamento.

Este trabalho, a partir da revisão crítica da literatura sobre o tema, argumenta que a governança climática privada tem um importante papel a desempenhar para aperfeiçoar o diálogo entre os regimes internacionais de clima e de comércio, especialmente em vista do atual cenário de crise do multilateralismo, em que atores para além do Estado assumem novos papéis, inclusive na produção de normas e padrões. A mudança do enfoque tradicional sobre Estados e governos para um enfoque na governança colaborativa público-privada pós-soberana permite reconhecer importantes ferramentas disponíveis para as estratégias de redução de emissões de gases de efeito estufa, com potencial inovador para aumentar eficácia das instituições multilaterais. Essas ferramentas, porém, trazem novos desafios em termos de imposição de limites, para se evitar novas formas de 
protecionismo e de estruturas de mercado monopolistas. Como vimos, o sistema de solução de controvérsias da OMC enfrenta dificuldades em julgar limites para as exceções ao livre comércio, quando políticas ambientais e climáticas implementadas por países confrontam as regras de livre comércio. O controle mostra-se obviamente mais desafiador se os padrões são estabelecidos por entes privados e difundidos por meio da contratação em cadeias de valor globais, na medida em que tais regulamentações privadas não se submetem ao sistema da OMC.

Para o futuro, é necessário o desenvolvimento de estratégias para se exigir prestação de contas das empresas quanto aos novos requisitos que inserem na contratação privada em cadeias de valor globais. Um primeiro passo seria maior transparência de informação, na medida em que existem poucas fontes públicas de contratos de fornecimento. A divulgação corporativa, não sendo obrigatória, demanda que a análise seja embasada em políticas e declarações liberadas voluntariamente (VANDENBERGH, 2007, p. 962). Seria tentador procurar no governo exigências legais para fortalecer a contratação privada, por meio, por exemplo, do incentivo à adoção de padrões específicos em cadeias de suprimento ambiental ou da exigência de divulgação de práticas existentes (VANDENBERGH, 2007, p. 969). As mesmas barreiras que impediram a ação do Estado até o momento, porém, se farão igualmente presentes neste caso. Os formuladores de políticas podem, no entanto, fomentar o desenvolvimento de contratos de cadeia de valor, criando ambientes nos quais a cooperação da empresa provavelmente não levará a comportamentos anticoncorrenciais. Mudanças na cultura e na estratégia das ONGs e de seus doadores, que permitam algum nível de colaboração com empresas privadas após a aplicação de pressão para adoção de padrões ambientais na contratação de fornecedores, serviriam também de apoio na moldagem de requisitos adequados para sua implementação. De maneira repressiva, as ONGs podem ainda fiscalizar a ação privada, por meio de boicotes e campanhas públicas de informação. Além disso, organismos coletivos de definição de padrões, como o ISO, podem ter um impacto nos incentivos para a contratação ambiental privada, se incluírem a contratação da cadeia de valor como um requisito para certificação ou conformidade com padrões coletivos (VANDENBERGH, 2007, p. 922). Todas essas alternativas merecem uma análise mais profunda, para potencializar os efeitos positivos da contratação climática privada sobre o nexo clima-comércio.

Por fim, o impacto para países em desenvolvimento também merece ser estudado de forma específica, sobretudo pela posição que estes tradicionalmente ocupam nas cadeias globais de valor, a exemplo de sua importância no fornecimento de matérias primas e de produtos de menor valor agregado, ficando em uma posição passiva de submissão a padrões climáticos elaborados por empresas importadoras, em sua maioria concentrada em países desenvolvidos. Os efeitos de bem-estar da contratação climática privada para os países em desenvolvimento, porém, seria tema para um trabalho futuro.

\section{Referências}

ABBOTT, K. W. The transnational regime complex for climate change. Environment and Planning C: Government and Policy, Thousand Oaks, v. 30, n. 4, 571-590, 2012. Disponível em: https://doi. org/10.1068/c11127. Acesso em: 16 go. 2019. https://doi.org/10.1068/c11127 
ALDEN, E. Trump, China, and Steel Tariffs: The Day the WTO Died. Council of Foreign Relations. [S. l.: s. n.], 2018. Disponível em: https://www.cfr.org/blog/trump-china-and-steel-tariffs-day-wto-died. Acesso em: 16 go. 2019.

BÄCKSTRAND, K. Accountability of networked climate governance: The rise of transnational climate partnerships. Global Environmental Politics, [S. l.], v. 8, n. 3, p. 74-102, 2008. https://doi. org/10.1162/glep.2008.8.3.74

BETSILL, M. M.; BULKELEY, H. Transnational Networks and Global Environmental Governance: The Cities for Climate Protection Program. International Studies Quarterly, Beverly Hills, Calif., US, v. 48, n. 2, p. 471-493, 2004. https://doi.org/10.1111/j.0020-8833.2004.00310.x

BHAGWATI, J. US Trade Policy: The Infatuation with FTAs. New YorK: Columbia University, 1995. (Discussion Paper Series, n. 726). Disponível em: https://doi.org/10.7916/D8CN7BFM. Acesso em: 16 go. 2019.

BRANDI, C. Trade Elements in Countries' Climate Contributions under the Paris Agreement. [S. l.]: ICTSD, 2017.

BRANDI, C.; BERGER, A.; BRUHN, D. Between Minilateralism and Multilateralism: Opportunities and Risks of Pioneer Alliances in International Trade and Climate Politics: briefing paper. Deutsches Institut für Entwicklungspolitik, Bonn, n. 16, p. [1-4], 2015.

CDP. Closing the Gap: Scaling up sustainable supply chains. CDP Supply Chain Report 2017/2018. [S. l.]: CDP, 2018.

DROEGE, S.; VAN ASSELT, H.; DAS, K.; MEHLING, M. The trade system and climate action: ways forward under the Paris Agreement: Working Paper. [S. l.]: Climate Strategies, 2016. Disponível em: https://climatestrategies.org/wp-content/uploads/2016/10/Trade-and-climate-ways-forward-1. pdf. Acesso em: 16 go. 2019.

DROEGE, S.; VAN ASSELT, H.; DAS, K.; MEHLING, M. Making the International Trade System Work for Climate Change: Assessing the Options. [S. l.]: Climate Strategies, 2018. Disponível em: https:// climatestrategies.org/publication/assessing-the-options/. Acesso em: 16 go. 2019. https://doi. org/10.2139/ssrn.2864400

FALKNER, R. Private Environmental Governance and International Relations: Exploring the Links. Global Environmental Politics, [S. l.], v. 3, p. 72-87, 2003. https://doi.org/10.1162/152638003322068227

GOLDTHAU, A., KEATING, M.; KUZEMKO, C. Nexus-thinking in International Political Economy: What energy and resource scholarship can offer international political economy. In: Handbook of the International Political Economy of Energy and Natural Resources. Cheltenham: Edward Elgar, 2018. p. 1-19. https://doi.org/10.4337/9781783475636

HOWLETT, M.; KEMMERLING, A. Calibrating climate change policies: The causes and consequences of sustained under-reaction. Journal of Environmental Policy \& Planning, Thousand Oaks, v. 19, n. 6, p. 625-637, 2017. https://doi.org/10.1080/1523908X.2017.1324772

KEOHANE, R.; VICTOR, D. The Regime Complex for Climate Change. Perspectives on Politics, New York, v. 9, n. 1, p. 7-23, 2011. https://doi.org/10.1017/S1537592710004068

KHOR, M. Challenges of the Green Economy Concept and Policies in the Context of Sustainable Development, Poverty and Equity. [S. I.: s. n.], 2012. p. 69-97. Disponível em: http://purochioe. rrojasdatabank.info/transition-4.pdf. Acesso em: 16 go. 2019. 
PATTBERG, P. The Institutionalization of Private Governance: How Business and Nonprofit Organizations Agree on Transnational Rules. Governance, Oxford, v. 18, n. 4, p. 589-610, 2005. https://doi.org/10.1111/j.1468-0491.2005.00293.x

ROSENAU, J. N. Change, Complexity, and Governance in Globalizing space. In: PIERRE, J. (ed.). Debating Governance: Authority, Steering, and Democracy. Oxford: Oxford University Press, 2000. p. 167-200.

UNITED NATIONS FRAMEWORK CONVENTION ON CLIMATE CHANGE (UNFCCC). Proposals by India for inclusion of additional agenda items in the provisional agenda of the seventeenth session of the Conference of the Parties. [S. l.: s. n.], 2011. Disponível em: https://unfccc.int/sites/default/ files/resource/docs/2011/cop17/eng/info2a01.pdf. Acesso em: 16 go. 2019.

VANDENBERGH, M. P. The New Wal-Mart Effect: The Role of Private Contracting in Global Governance. UCLA Law Review [S. l.], v. 54, p. 913, 2007.

VANDENBERGH, M. P.; GILLIGAN, J. M. Beyond Politics: The Private Governance Response to Climate Change. Cambride, UK: Cambridge University Press, 2017. https://doi.org/10.1017/9781316848555 WENDT, A. Anarchy is what states make of it: The social construction of power politics. International Organization, Cambridge, Mass., v. 46, n. 2, p. 391-425, 1992. https://doi.org/10.1017/ $\underline{\text { So020818300027764 }}$

YANDLE, B. Bootleggers and Baptists: The Education of a Regulatory Economist. AEI Journal on Government and Society, [S. l.], p. 12-16, 1983.

YU, V. P. The New Climate Protectionism: Analysis of the trade measures in the US climate bill. South Bulletin. [S. l.], n. 40, p. 5-7, 10 Sept. 2009. Disponível em: http://www.twn.my/title2/climate/info.service/2009/20090902/South.Bulletin.40.of.10sepo9.on.Climate.Protection.pdf. Acesso em: 16 go. 2019.

Recebido: $18 / 02 / 2019$

Aceito: 13/05/2019

\section{Biografia do autor}

\section{Karina Marzano Franco}

MBA em Relações Internacionais da Fundação Getulio Vargas (FGV). Mestre em Direito Europeu e da Integração pelo Europa-Institut da Universidade de Saarland, Alemanha. Bacharel em Direito pela Universidade Federal de Minas Gerais (UFMG). ORCID: http://orcid.org/o000-0002-6826-821X; E-mail: karina.marzano@hotmail.com

Instituição: Fundação Getúlio Vargas, FGV, Brasil.

Localização: Edifício Luiz Simões Lopes (Sede - Praia de Botafogo, 190 - 11 Andar - Botafogo, Rio de Janeiro - RJ, 22250-900 